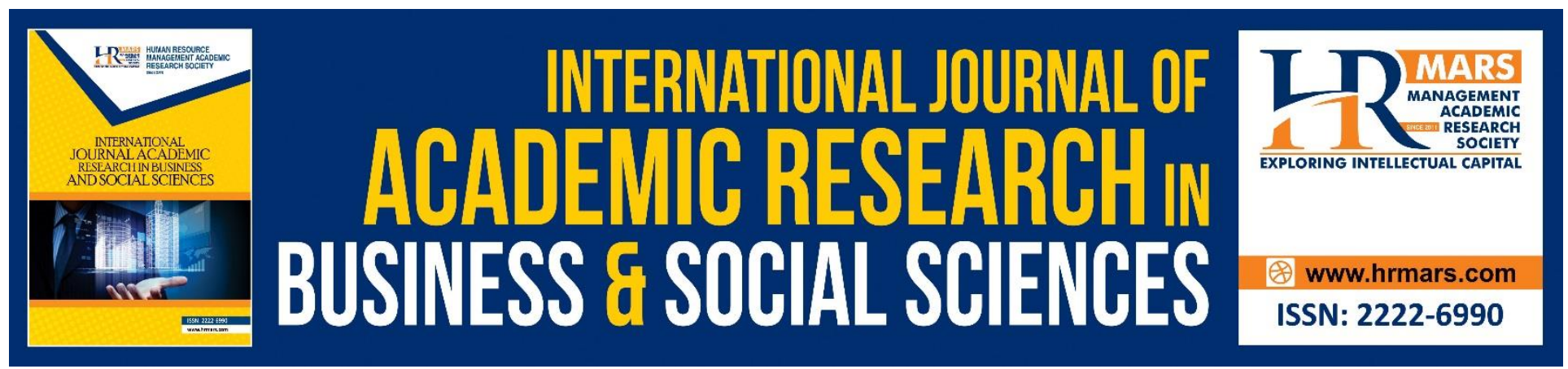

\title{
The Impact of Digital Divide on the Quality of University Education
}

\section{Nawaf Hamad Obaid Al Kaabi, Farid Qawasmeh}

To Link this Article: http://dx.doi.org/10.6007/IJARBSS/v10-i11/8125
DOI:10.6007/IJARBSS/v10-i11/8125

Received: 07 September 2020, Revised: 29 September 2020, Accepted: 15 October 2020

Published Online: 08 November 2020

In-Text Citation: (Al Kaabi, \& Qawasm, 2020)

To Cite this Article: Al Kaabi, N. H. O., \& Qawasmeh, F. (2020 The Impact of Digital Divide on the Quality of University Education. International Journal of Academic Research in Business and Social Sciences. 10(11), 565578.

\section{Copyright: (c) 2020 The Author(s)}

Published by Human Resource Management Academic Research Society (www.hrmars.com)

This article is published under the Creative Commons Attribution (CC BY 4.0) license. Anyone may reproduce, distribute, translate and create derivative works of this article (for both commercial and non-commercial purposes), subject to full attribution to the original publication and authors. The full terms of this license may be seen

at: http://creativecommons.org/licences/by/4.0/legalcode

\section{Vol. 10, No. 11, 2020, Pg. 565 - 578}

Full Terms \& Conditions of access and use can be found at http://hrmars.com/index.php/pages/detail/publication-ethics 


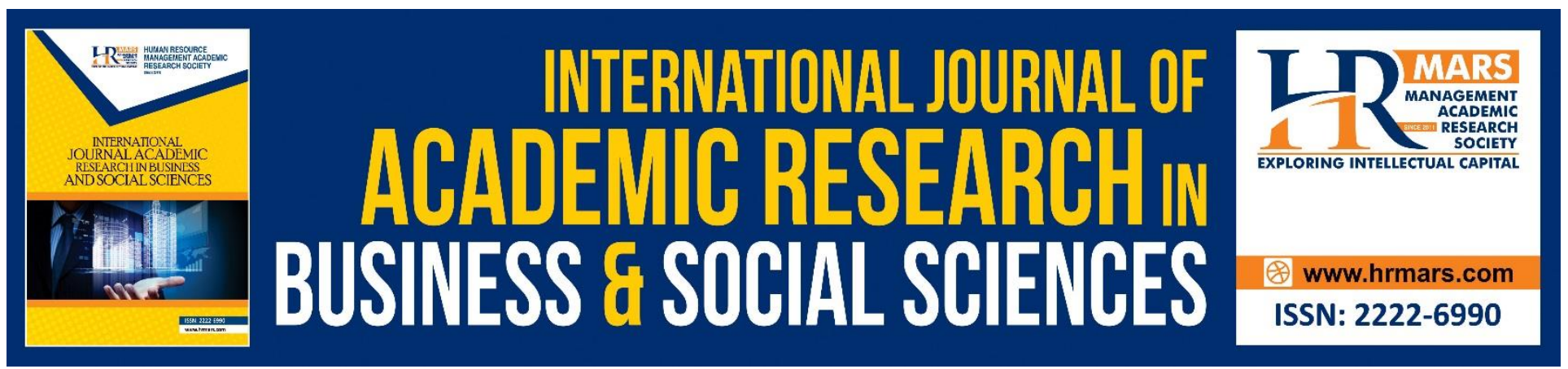

\title{
The Impact of Digital Divide on the Quality of University Education
}

\author{
Nawaf Hamad Obaid Al Kaabi, Dr. Farid Qawasmeh \\ Department of Business Administration -Business Collage- JADARA University, Jordan
}

\begin{abstract}
This study is aimed at identifying the impact of digital divide on the quality of university education at Jordan private University in the north region, and the descriptive analytical approach has been used to suit the nature of the study so as to design the appropriate tool through the questionnaire, as it was distributed to a sample of (250) of the faculty members as a representative sample of the study community. The most important results were is represented by the fact that there is statistically significant effect at the level of significance $(\alpha<0.05)$ of the digital divide with its dimensions (Digital reach, digital ability divide, digital results divide) on the quality of the university education in its dimensions (Strategic vision of leadership, academic reputation, quality of students (graduates), besides the quality of scientific research, as well as the quality of a university professor).
\end{abstract}

Keywords: Digital Divide, Quality of University Education, Private Universities, Jordan.

\section{Introduction}

Despite the policies and efforts to close the access divide, the United Nations indicated that the digital divide has not diminished. Indeed, it is growing on a larger scale (United Nations, 2010). However, some scholars have argued that understanding the digital divide at the time was not quite comprehensive and led to inadequate policies. In light of this fact, Dewan and Frederick (2005) have suggested two variants of the digital divide. The first ranking indicates to the access divide, meanwhile the second indicates the capacity divide, which is represented by the inequality in the ability to use technology among those who already have access. Moreover, Tan et al., (2011), emphasized that there is a divide called "The results divide", which is an inequality in the results of technology exploitation resulting from the first and second degree digital divides.

Regardless of the differences on defining the digital divide, it is quite clear that there is a need for a comprehensive understanding of this issue and its impact on the quality of university education, especially as information systems have improved and changed the way organizations operate (Mahfodh \& Obeidat, 2020). A divide therein leads to a great challenge for organizations since information systems, technology and their use including the use of the Internet, contribute to improving and enhancing the creativity and innovation capacity of the educational institution because of the improvements made which provides in saving time and effort, besides the delivery of information and data in a smooth manner for both the teacher and the learner, as it achieves a high 
INTERNATIONAL JOURNAL OF ACADEMIC RESEARCH IN BUSINESS AND SOCIAL SCIENCES Vol. 10, No. 11, 2020, E-ISSN: 2222-6990 ๑ 2020 HRMARS

degree of efficiency and effectiveness in the process of transferring, exchanging, sharing, monitoring and controlling information in the field of the educational process and working on controlling its quality.

In addition, higher education institutions seek more success and progress and reach high levels of classification at the educational level if compared to other educational institutions, whether at the local or global level (Aljawarneh et al, 2020). Besides, successes can be achieved for those Institutions through their application of local and international quality standards. Therefore, it appears here the need for getting rid of the throwing divide by using the highest standards of information technology and Internet delivery and its application in reaching a high quality befitting the reputation of educational institutions at the local and global level, where quality is focused in the field of university education on the academic experiences and workers in these institutions and in the educational fields.

Along with the increasing availability of digitally advanced technologies in nearly every aspect of our lives, the need for appropriate digital and information literacy skills increases. Accordingly, and in this world of changing technologies, digital skills are considered as one of the most important life skills (Irtaimeh et al, 2016). Hence, the introduction of these technologies including information and communication technology (ICT), provides valuable resources for the academic and social development of learners, where new learning activities, expanding collaborations, introducing new assessment models and presenting curriculum content using visual stimulants have been made, and all of which were missing in traditional learning. In addition, the proper integration of tools, systems and services supported with appropriate technology helped transform traditional teaching and learning environments with new practice methods. Therefore, and despite the innovative potential of information and communication technology to improve learning outcomes for each learner, integrating information and communication technology into the learning process represents a challenge, may lead to highlighting the existing digital divides, and, thus, leads to improving or decreasing the quality of university education. Therefore, the problem of this study came to answer the following main question: "Is there any effect of the digital divide on the quality of higher education in Jordanian private universities in the Northern Region.

\section{The Digital Divide}

The problem of the digital divide has become one of the biggest challenges posed by the communications technology revolution among users in the information technology space including employees, organizations, and countries, thus, creating a divide between the two layers of "Information's rich people" and "information's poor people". Consequently, this has led to the attention of users, individuals, organizations, states and governments to this problem, which has become the subject of research to ensure that there is no balance between the structures of societies in their multiple layers (Al-Ahmad et al., 2018). At the World Summit on the Information Society (WSIS) held in December 2003, the Heads of States and Governments from around the world declared that the global challenge of the new millennium is to build a society in which all can access and share information, and to empower individuals and societies to realize their full potential in promoting their development and improving the quality of their lives (Krause, 2012). In a report of the United Nations, it provides that the societies must cooperate to build the capacity of civil societies and improve their participation, in addition to creating opportunities and ending obstacles to obtaining information, creating an environment and enabling societies to do so. The report added that information 
INTERNATIONAL JOURNAL OF ACADEMIC RESEARCH IN BUSINESS AND SOCIAL SCIENCES Vol. 10, No. 11, 2020, E-ISSN: 2222-6990 @ 2020 HRMARS

technology facilitates the flow of information between countries, governments and users. So, it is necessary to work on enhancing and improving the opportunities for utilizing information technology in bridging the digital divide (Krause, 2012). Accordingly, the digital divide is defined as the lack of access by segments of society to information and communication technology. Hence, digital divide is a general term used to describe this lack of access for linguistic, economic, educational, social and geographic reasons. The divide [Gap] between those people and societies who can access and benefit from information technology effectively and those who cannot (Ayad, 2017) are used to describe the contradiction between people who have access and the resources needed to use information and new communication tools, such as the Internet, and people who do not have the resources and access to technology (Park and Lee, 2015).

To close this divide, whether for financial, geographical or economic reasons, at the local, national or international levels, does not only mean providing computers to the people who need them. This means we also train them on using computers, and most importantly, we teach them on how to access information. Besides, access includes not only knowing where the information is located, but, also, how to understand it, and how to use it wisely. Therefore, it is necessary to create an environment and information centers that allow free and fair access to information as well as freedom of expression and action to participate in knowledge-focused societies (Yu et al. ., 2018; Obeidat \& Otibi, 2015), and the phenomenon of the digital divide has been studied and understood in different ways across different contexts. But, the most common perspective regarding digital divide research is unequal access to technologies, while some other research extends beyond inequality in digital skills and even on how they are used. However, the common understanding behind most research is represented by the fact that the digital divide is a complex issue, and it is difficult to understand the phenomenon in one context and with one definition. A close examination of the literature does not give any clear evidence as to the origin of the term "digital divide" and its meaning remains unclear. For this reason, the phenomenon of the digital divide has been described by several authors as the most pressing social, economic and academic issue of the information age and is now receiving increased attention from researchers and policy-makers around the world (Adhikari et al., 2016).

(Adhikari et al., 2016) classifies the dimensions of the digital divide into three different types based on the nature and type of factors associated with it:

First: The digital access divide, which is the divide between those who have access to information and communication technology and various forms of digital technologies and those who do not possess them. For many years during the initial study on the digital divide, it was considered as the only definition, and, thus, the meaning of the digital divide was interpreted in a major form within the context of accessing digital technologies. Accordingly, the specialized studies in this aspect have identified some specific factors for the divides between haves and have-nots, financial condition, family income, educational level, occupation type and geographic location as the most common factors. This indicates that individuals and societies with low financial status and educational level may have limited or no access to technology and digital media (Adhikari et al., 2016).

Second: The capacity divide which simply means that providing access to technology to individuals may not be sufficient to ensure that they use the media appropriately to meet their needs and expectations, as the people who have been provided with access to technologies must also possess the digital skills to benefit usefully from the available technologies. Otherwise, in the absence of basic digital skills, the digital divide will still exist in the form of skills divide, as the digital divide has been 
INTERNATIONAL JOURNAL OF ACADEMIC RESEARCH IN BUSINESS AND SOCIAL SCIENCES Vol. 10, No. 11, 2020, E-ISSN: 2222-6990 @ 2020 HRMARS

classified into two different levels, namely, level one (Access to information and communication technology) and level two (Ability to use technology properly). (Adhikari et al., 2016).

Third: The digital divide is a more recent analysis of the phenomenon and is also referred to as the level three digital divide. Therefore, it is defined as the inequality in the outcomes achieved by users of technology and digital media based on the relevant factors such as the individual's attitude and motivations towards technology, besides the nature of the use of this technology and the ability to make meaning. A recent study conducted on primary school students also proves that the factors associated with motivation have significant influence on how the digital divide is formed in the educational context. However, factors related to motivation are themselves shaped by complex interactions of events, such as access to computers and the Internet at home, as well as the active use of technology by parents, and, overall, provides good experience in using the school's technology and computing environment. (Adhikari et al., 2016).

\section{Quality of Higher Education}

It is worth stating that not all efforts have been successful for the correct application of TQM in the fields of higher education. Concepts related to quality management do not always have a significant impact on the prevailing concepts and practices of quality education. This may be attributed to the fact that there is still no global consensus on the best way to manage quality in education. It is not always successful (Hamed and Al-Abed, 2012; Saffar, \& Obeidat, 2020) to borrow TQM ideas from the industry for use in education. Moreover, the deployment of quality management in the education sector is certainly not an easy thing, as many obstacles must be overcome in order to be successful. Keeping this in mind, many researchers and specialists in higher education institutions remain skeptical about adopting quality management in the areas which are dependent on education (Madi, 2011). Therefore, some higher education institutions in countries and internationally in the Arab world, especially Jordan, suffer from many challenges including the low quality of outputs and their inconsistency with the requirements of the labor market needs in most Arab countries equally. Besides, many of the specializations and programs of these institutions no longer constitute a priority for the needs of society. Consequently, the local labor market has become saturated with it, and this is all about ensuring the quality of higher education. Furthermore, the use of information and communication technology and the types of contemporary knowledge is an effective use and not a formal use in order to help the learner acquire the knowledge, skills, techniques and methodology that enable him to be able to produce and create (Madi, 2011; Obeidat, 2019). In addition to the ever-changing higher education environment, the increasing demands of organizations regarding the quality of education, changing expectations of students and employers regarding the content and methods of study, and the increasing financial pressure in the public sector, increasing competition between universities, not only encourages educational institutions, but forces them to search for new methodological measures to improve and manage educational quality (Badrakhan, 2013)

Quality management in education refers to "A cooperative system in which both customers (Students) and suppliers (Faculty members) mutually agree and continuously meet clients' needs, requirements and expectations." The problem with this definition is represented by the fact that an educational system is multifaceted with diverse groups of clients and stakeholders that are diverse and contradictory often have differing, opposing and even conflicting expectations and resulting requirements (Munasinghe \& Rathnasiri, 2011). In addition, the quality of education indicates also that it cannot be evaluated with a single indicator. However, whatever indicators or metrics were 
INTERNATIONAL JOURNAL OF ACADEMIC RESEARCH IN BUSINESS AND SOCIAL SCIENCES Vol. 10, No. 11, 2020, E-ISSN: 2222-6990 @ 2020 HRMARS

developed to measure, customer satisfaction will remain the main focus (Student satisfaction), understanding customer expectations is essential, in order to be able to design systems that can lead to customer (Student) satisfaction (Al-Khatib, 2013). Moreover, (Al-Mahamid, 2008) indicated that the ability to understand customer expectations is qualified to provide superior products, because it embodies the performance measures / standards that customers use in evaluating quality. It also refers to "A set of standards and procedures whose implementation aims at continuous improving the educational product and to the specifications and characteristics expected in the educational product and in the processes and activities through which these specifications are achieved. It also provides integrated tools and methods that help educational institutions achieve results Pathology "(Nasima, 2017). Krause (2012) define education quality as the inputs, processes and outputs of an education system that provides services that fully satisfy both internal and external strategic circles by meeting their explicit and implicit expectations. Quality of education is an overarching concept that includes the quality of inputs in the form of students, faculty, technical and administrative personnel, infrastructure and capital; Process quality in the form of teaching, learning and administrative activity; and the quality of the outputs in the form of enlightened students of high quality exiting the system. Accordingly, the quality of education means the ability of the institution or university at all its levels that help it to prepare students who are able to fulfill the needs of the labor market according to what has been prepared from the specifications (Naqra and Tarawneh, 2018). Hence, the quality of higher education is a multi-faceted concept, so that it includes all jobs and activities: curricula and programs, faculty member qualifications and facilities, student characteristics, organization and administration, and interactive networks (Al-Ali, 2017).

Numerous studies (Al-Naqry \& Al-Tarawanah, 2018; Al-Ali, 2017) have indicated to the benefits of applying and adopting quality management in higher education institutions (Tsinidou et al 2010, Naqry \& Al-Tarawana, 2018; Al-Ali, 2017). There is no doubt that, the benefits of service industries such as education are no less than those of manufacturing, if properly applied and adopted (In other words, quality management principles and tools can make a real difference with regard to the success and performance of the universities and higher education institutions. Besides, there is a significant impact of quality management on mechanisms of improvement and outcomes in education, which contributes to the social and economic well-being of the country. Ruzevicius et al., (2007), specified that quality management education can make a significant contribution to higher education institutions, such as financial savings, enhanced morale, improved performance, increased responsiveness, improved customer service and operations, and developed a sense of teamwork. Meanwhile, Venkatraman (2007) stated that in higher education, management is considered as a total quality and a practical approach to increasing productivity, reducing costs, and improving service quality. However, Krause (2012) observed that universities apply total quality management to improve teaching, measure student satisfaction, improve curricula, measure employee satisfaction, and improve university operations. (2013) one student and others have examined the benefits of the comprehensive quality management within the service industries in terms of quality, service quality, employee service quality, employee satisfaction, customer's satisfaction and supplier performance. On the other side, Kantabutra (2010) identified the advantages of TQM in service organizations such as improving productivity, increasing customer satisfaction, increasing employee morale, improving management-work relations, and higher overall performance (Shrous et al, 2020). 
According to Venkatraman (2007), the basic core values that form the fundamental building blocks of the TQM framework for higher education preparation are the following: a culture of leadership and quality, continuous improvement and innovation in educational processes, employee participation and development, rapid response and management information and quality Customerdriven and partnership development. In addition, O'Mahony and Garavan (2012) stated that the factors which are relevant to an understanding of the implementation of quality management systems in higher education include the commitment and stewardship of senior management (Communicating a clear statement of mission, using an enabling approach, data, information and knowledge of best practices in a timely manner), stakeholder engagement (Employee empowerment, middle management engagement), creating a culture of continuous improvement and focusing on process issues (Self-assessment, internal auditing, comparison, management by process, measurement, information, analysis, quality management system adoption and evidence-based approach to decision-making. ). Likewise, Svensson and Klefsjo (2006) indicated that there is a common basis for core values that constitute a framework for TQM-based self-assessment in the education sector. Furthermore, these values include customer focus and operations, continuous improvement, fact-based decision-making, employee commitment and leadership (Al- thani \& Obeidat, 2020; Malkawi et al, 2017).

Accordingly, ten critical factors for quality management that are relevant to quality initiatives in a higher education context have been identified; these include: leadership insight, customer focus, effective communication, consistent or appropriate goals, employee selection and appointment, competent employees, teamwork spirit, training and education, recognition and motivation, innovation and creativity. Meanwhile, the Total Quality Management Framework for Engineering Education proposed by Mehta et al. (2014) included corporate resource management, long-term strategy and planning, excellence in human resource management (Al-qudah et al, 2020), continuous evaluation and improvement, senior management commitment and leadership, student focus, and employee focus, graduates' focus, information management system, quality message, vision statement, service culture, philosophy, innovative academic style, industry and institutional partnership. In this context, (Mehta et al., 2014) strongly recommended that a set of TQM frameworks be implemented for future research on TQM. Such framework includes the following basic elements of TQM: leadership, commitment to senior management, and planning strategic for quality, faculty, staff management and participation, supplier management, student focus, operations management, continuous improvement, information and analysis, knowledge and education. Meanwhile (Ayyad, 2017) indicated that the dimensions of the quality of education applied in Western universities: focus on meeting student requirements; continuous improvement of the quality of services provided to students; participation of all employees in the improvement processes; participation of the organization's partners in quality management; management's commitment to the highest level of quality; vision and dissemination of the organization; decisions based on a systematic analysis of data; training of all employees seeking to change their attitudes towards quality; and working in a spirit of teamwork.

It is worth mentioning that higher education institutions use several methods to improve effectiveness and choose to search for quality and excellence. However, depending on the preferences and motives of a particular organization, different goals for quality can be set. Hence, improving quality are the reasons for the universities to be strive for quality and excellence. But, regarding the internal needs of the organization which is the primary motivation in most universities 
INTERNATIONAL JOURNAL OF ACADEMIC RESEARCH IN BUSINESS AND SOCIAL SCIENCES Vol. 10, No. 11, 2020, E-ISSN: 2222-6990 @ 2020 HRMARS

to implement it, the universities seek to obtain a better image or are concerned about increasing and sustaining the market share because it is assumed that the quality they possess an indication to the clients which the organization is striving for high quality (Muhammad, 2017)

\section{Study Methodology}

In order to answer the study questions and discuss its hypotheses; this study relied on the descriptive and analytical approach to study the impact of the digital divide on the quality of university education, an applied study on Jordanian private universities in the northern region, with measuring the dimensions of each one of them, and relying on the questionnaire to collect the necessary data on the study variables; where the study population included members of the faculty in private universities in the northern region (Jerash University, Jadara University, Irbid National University, Ajloun National University) and a number of 700 faculty members, where the sample included (250) individuals, and was chosen in a simple random sample, where most of them were males, with the rank of assistant professor, and most of them had experiences ranging from 5-15 years. Table No. (1) Illustrate this part of the study.

Table (1) Description of the study sample according to the personal variables of the study members

\begin{tabular}{clll}
\hline \multirow{2}{*}{ Variable } & \multicolumn{1}{c}{ Category } & Number & Percentage \\
\hline \multirow{2}{*}{ Gender } & Male & 189 & 75.6 \\
& Female & 61 & 24.4 \\
\cline { 2 - 3 } Rank of faculty member & Assistant Professor & 161 & 64.4 \\
& Associate Professor & 76 & 30.4 \\
\cline { 2 - 4 } Administrative level & Professor Dr. & 13 & 5.2 \\
\cline { 2 - 3 } Years of experience & Senior management & 95 & 38.0 \\
& Middle management & 155 & 62.0 \\
& Less than 5 years & 45 & 18.0 \\
& 5-Less than 10 years & 102 & 40.8 \\
& 10- Less than 15 years & 68 & 27.2 \\
& 15 years and over & 35 & 14.0 \\
\hline
\end{tabular}

\section{Study Model and Hypotheses}

The model of this study was built depending on the theoretical literature, and the opinions of researchers in the field of study. Figure No. (1) illustrates the model of the study, where three hypotheses were developed, which is as follows:

H01: There was no statistically significant effect at $(\alpha<0.05)$ level of the digital access divide on the quality of university education.

H02: There is no statistically significant effect at the level of significance $(\alpha<0.05)$ of the digital ability divide on the quality of university education.

H03: There is no statistically significant effect at the level of $(\alpha<0.05)$ of the digital results divide on the quality of university education. 


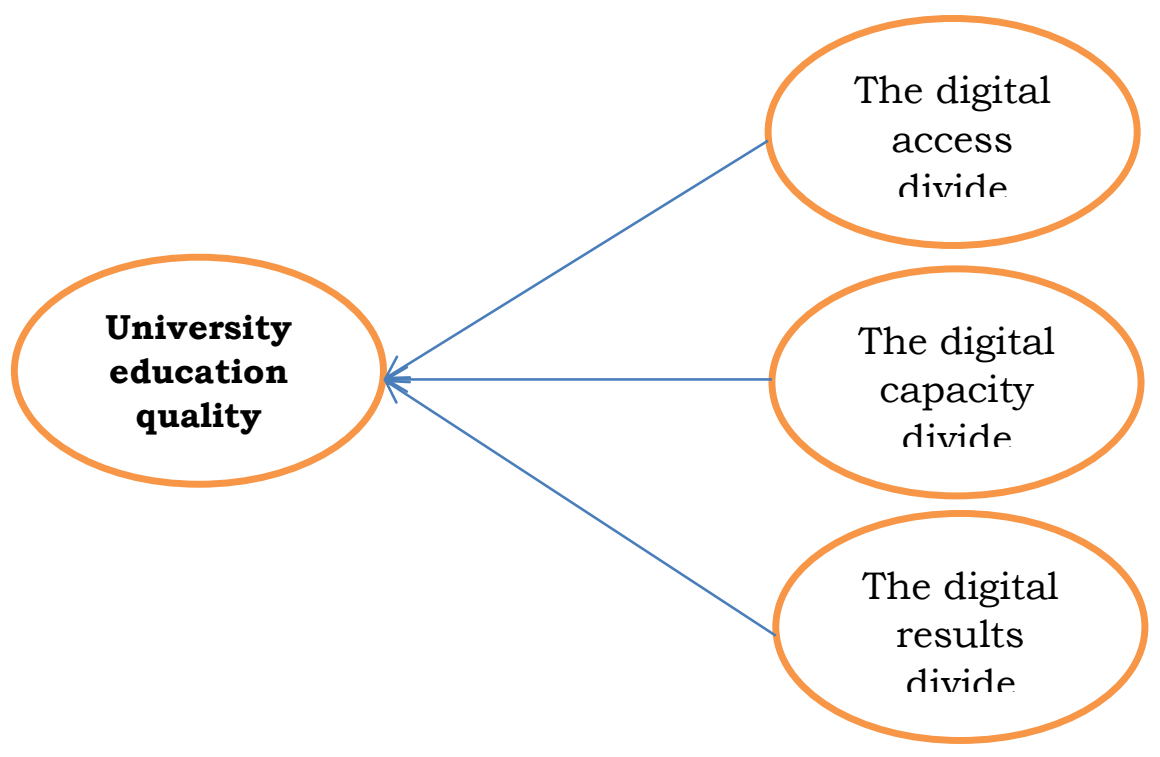

\section{The Validity and Reliability of the Study Tool}

In order to verify the validity of the study tool, the questionnaire was presented to the arbitrators who are specialized in departments of faculties of administration, and were chosen from many universities to judge its validity (Apparent truthfulness), with the aim of identifying the availability of the following aspects in the study tool: besides the accuracy of the linguistic wording and clarity in the paragraphs of the questionnaire, the extent to which the paragraphs are appropriate to the dimension to which they belong, the extent of the appropriateness and comprehensiveness of the questionnaire for all dimensions that measure the study variables. In addition, the stability of the tool was also confirmed, as the Cronbach alpha equation was used on the study sample, in order to find out the coefficient of stability of the internal consistency for each of the measurement fields, as the values of the stability coefficients for the measurement fields ranged between (0.790-0.937), which are high and sufficient for the purposes of the study and to know those values. Table (3) shows that:

\section{Table (2) the value of the stability coefficient (Kernbach Alpha) for the study variables}

\begin{tabular}{ll}
\hline \multicolumn{1}{c}{ The field } & $\begin{array}{c}\text { Cronbach's alpha } \\
\text { Value }\end{array}$ \\
\hline The digital access divide & 0.801 \\
The digital capacity divide & 0.790 \\
The digital results divide & 0.807 \\
The divide scale as a whole & 0.893 \\
Education quality scale & 0.937 \\
\hline
\end{tabular}

\section{Descriptive Statistics}

The arithmetic averages and standard deviations were calculated to estimate the responses of the sample members on each dimension of the digital divide and the dimensions as a whole. Table (3) illustrates this point: 
INTERNATIONAL JOURNAL OF ACADEMIC RESEARCH IN BUSINESS AND SOCIAL SCIENCES Vol. 10, No. 11, 2020, E-ISSN: 2222-6990 @ 2020 HRMARS

Table (3): The arithmetic averages and standard deviations of the estimates of the respondents of the sample on each dimension of the digital divide

\begin{tabular}{|c|c|c|c|c|c|}
\hline Variable & Dimension & mean & S D & \multirow{2}{*}{$\begin{array}{l}\text { Level } \\
\text { Medium }\end{array}$} & \multirow[t]{2}{*}{ Rank } \\
\hline $\begin{array}{l}\text { Dependent } \\
\text { Variable }\end{array}$ & University education quality & 3.560 & .713 & & \\
\hline \multirow{3}{*}{$\begin{array}{l}\text { Independent } \\
\text { Variables }\end{array}$} & The digital results divide & 3.799 & .810 & High & 1 \\
\hline & The digital access divide & 3.744 & .818 & High & 2 \\
\hline & The digital capacity divide & 3.584 & .829 & Medium & 3 \\
\hline \multicolumn{2}{|c|}{ The digital divide as a whole } & 3.703 & .704 & High & \\
\hline
\end{tabular}

*Greatest degree (5)

It turned out to us from Table (3) that the arithmetic averages of the study dimensions ranged from (3.584-3.799) with a high and medium degree of agreement, where the highest dimension was the "Digital results divide", then, the arithmetic mean (3.744) for the dimension "The digital access divide". Meanwhile, the lowest for the dimension was "The digital capacity divide" and the arithmetic average of the dimensions as a whole was (3.703) with a high degree of approval. In addition, the arithmetic means and standard deviations were calculated also for the estimates of the respondents 'responses to the quality of university education.

\section{Hypothesis Testing}

In order to ensure the validity of the sub-hypotheses, a simple linear regression test was applied to find out whether there is a statistically significant effect of the independent variable on the dependent variable, and the following is a presentation of the same:

First hypothesis test: There is no statistically significant effect at the level of significance $(\alpha<0.05)$ of the digital access divide on the quality of university education.

Table (4): * Results of the first hypothesis test, H01

\begin{tabular}{|c|c|c|c|c|c|c|c|c|c|}
\hline \multicolumn{5}{|c|}{ Coefficient } & \multicolumn{2}{|c|}{ ANOVA } & \multicolumn{2}{|c|}{$\begin{array}{c}\text { Model } \\
\text { Summary }\end{array}$} & \multirow[t]{2}{*}{$\begin{array}{c}\text { Dependent } \\
\text { Variable }\end{array}$} \\
\hline Sig $t^{*}$ & $\mathrm{~T}$ & $\begin{array}{l}\text { Std } \\
\text { Error }\end{array}$ & B & $\begin{array}{l}\text { Descriptio } \\
n\end{array}$ & $\begin{array}{l}\text { Sig } \\
\mathrm{F}^{*}\end{array}$ & $\mathrm{~F}$ & $r^{2}$ & $\mathrm{R}$ & \\
\hline 0.000 & $\begin{array}{l}13.51 \\
8\end{array}$ & 0.042 & 0.568 & $\begin{array}{l}\text { The digital } \\
\text { access } \\
\text { divide }\end{array}$ & $\begin{array}{l}0.00 \\
0\end{array}$ & 15.721 & 0.424 & 0.651 & $\begin{array}{l}\text { University } \\
\text { Education } \\
\text { Quality }\end{array}$ \\
\hline
\end{tabular}

*The effect is statistically significant at ( $\alpha \leq 0.05)$

From table $(4)$, it is noticed that the value $(P=13.518)$ and in statistical terms $(0.00)$, which is less $(0.05 \geq \alpha)$; this indicates to the presence of an explanatory and significant force for using the simple regression analysis model, and, thus, the simple linear regression model is suitable for measuring the causal relationship; besides, the value of the correlation coefficient between the independent variable and the dependent variable amounted to (0.651), and the value of (2 R) (0.424), which indicates that the independent variable was able to explain $(2.42 \%)$ of the changes occurring In the dependent variable and the remainder they are attributed to other factors. Thus, it can be said that the independent variable affects the dependent variable, as the value $(T=13.518)$ and in statistical terms (0.00), which is less $(0.05 \geq \alpha)$. 
INTERNATIONAL JOURNAL OF ACADEMIC RESEARCH IN BUSINESS AND SOCIAL SCIENCES

Vol. 10, No. 11, 2020, E-ISSN: 2222-6990 @ 2020 HRMARS

The second hypothesis test: There is no statistically significant effect at the level of significance ( $\alpha$ $<0.05$ ) of the digital ability divide on the quality of university education

Table (5): * Results of the second hypothesis test, $\mathrm{HO2}$

\begin{tabular}{|c|c|c|c|c|c|c|c|c|c|}
\hline \multirow[t]{2}{*}{$\begin{array}{c}\text { Dependent } \\
\text { Variable }\end{array}$} & \multicolumn{2}{|c|}{$\begin{array}{l}\text { Model } \\
\text { Summary }\end{array}$} & \multicolumn{2}{|c|}{ ANOVA } & \multicolumn{5}{|c|}{ Coefficient } \\
\hline & $\mathrm{R}$ & $r^{2}$ & $\mathrm{~F}$ & Sig $\mathrm{F}^{*}$ & Description & B & $\begin{array}{l}\text { Std } \\
\text { Error }\end{array}$ & $\mathrm{T}$ & Sig $t^{*}$ \\
\hline $\begin{array}{l}\text { University } \\
\text { education quality }\end{array}$ & 0.636 & 0.405 & 168.799 & 0.000 & $\begin{array}{l}\text { The digital } \\
\text { capacity divide }\end{array}$ & 0.547 & 0.042 & 12.992 & 0.000 \\
\hline
\end{tabular}

*The effect is statistically significant at ( $\alpha \leq 0.05)$.

It is noticed from table $(5)$ that the value $(P=168.799)$ and in statistical terms $(0.00)$, which is less $(0.05 \geq \alpha)$; indicates to the presence of an explanatory and significant force for using the simple regression analysis model, and, thus, the simple linear regression model is suitable for measuring the causal relationship; besides, the value of the correlation coefficient between the independent variable and the dependent variable amounted to (0.636), and the value of (2 R) (0.405), which indicates that the independent variable was able to explain (5.40\%) of the changes occurring. In the dependent and the remainder variable they are attributed to other factors. Thus, it can be said that the independent variable affects the dependent variable, as the value of $(T=12.992)$ and in statistical terms $(0.00)$, which is less $(0.05 \geq \alpha)$

The third hypothesis test:

There is no statistically significant effect at the level of significance $(\alpha<0.05)$ of the digital results divide on the quality of university education

Table (6): * Results of the third hypothesis test, $\mathrm{HO2}$

\begin{tabular}{|c|c|c|c|c|c|c|c|c|c|}
\hline \multirow{2}{*}{$\begin{array}{l}\text { Dependent } \\
\text { Variable }\end{array}$} & \multicolumn{2}{|c|}{ Model Summary } & \multicolumn{2}{|c|}{ ANOVA } & \multicolumn{5}{|c|}{ Coefficient } \\
\hline & $\mathrm{R}$ & $r^{2}$ & $\mathrm{~F}$ & $\begin{array}{l}\text { Sig } \\
\mathrm{F}^{*}\end{array}$ & $\begin{array}{l}\text { Descriptio } \\
n\end{array}$ & B & $\begin{array}{l}\text { Std } \\
\text { Erro } \\
r\end{array}$ & $\mathrm{~T}$ & Sig $t^{*}$ \\
\hline $\begin{array}{l}\text { University } \\
\text { education quality }\end{array}$ & 0.632 & $\begin{array}{l}0.39 \\
9\end{array}$ & $\begin{array}{l}164.81 \\
6\end{array}$ & $\begin{array}{l}0.00 \\
0\end{array}$ & $\begin{array}{l}\text { The digital } \\
\text { results } \\
\text { divide }\end{array}$ & $\begin{array}{l}0.55 \\
6\end{array}$ & $\begin{array}{l}0.04 \\
3\end{array}$ & $\begin{array}{l}12.83 \\
8\end{array}$ & 0.000 \\
\hline
\end{tabular}

*The effect is statistically significant at $(\alpha \leq 0.05)$

Table (6) shows that the value $(P=164.816)$ and in statistical terms $(0.00)$, is less $(0.05 \geq \alpha)$; which indicates to the presence of an explanatory and significant force for using the simple regression analysis model, and, thus, the simple linear regression model is suitable for measuring the causal relationship; besides the value of the correlation coefficient between the independent variable and the dependent variable amounted to (0.632), and the value of $(2 \mathrm{R})(0.399)$, which indicates that the independent variable was able to explain (9.39\%) of the changes occurring. Meanwhile, in the dependent variable and the remainder they are attributed to other factors. Thus, it can be said that the independent variable affects the dependent variable, as the value $(t=12.838)$ and in statistical terms (0.00), which is less than $(0.05 \geq \alpha)$. 
INTERNATIONAL JOURNAL OF ACADEMIC RESEARCH IN BUSINESS AND SOCIAL SCIENCES Vol. 10, No. 11, 2020, E-ISSN: 2222-6990 @ 2020 HRMARS

\section{Result}

The researcher, in this chapter, reviewed the summary of the findings of the field study after polling the sample of the researched study opinions regarding (The impact of the digital divide on the quality of university education, an applied study on Jordanian private universities in the northern region), where the study concluded that the general average of the dimensions of the digital divide came to a high degree. The reason is referred to the fact that most of the faculty members use traditional methods of obtaining and searching for information and it is consistent with the study of Shaath (2012), in which the results concluded that there is a digital divide in the libraries of the university under study. It also agrees with the study of Shaath (2012), in which the results indicated that there is a digital divide in the libraries of the university, the subject matter of the study, and with the study of Al-Ahmad et al. (2018), which indicated that the solution to the digital divide does not depend on the provision of devices only, but, it is exposed to a set of obstacles including qualification and training of employees. Furthermore, the general average of the dimensions of the quality of university education was of an average degree, and the reason is represented by the fact that the university administration directs to this type of education and consolidates it to serve the educational community which is consistent with the Bagoor Study (2016), whose results indicated an impact between information technology and the quality of higher education in its different dimensions, which differs with Faraj's study (2019), whose results indicated that the general average of the reality of professional development in the field of professional aspects was weak. "It also agrees with the study of Asoul (2016), which indicated that communication and information technology has a great role in the quality of higher education for its users represented in libraries and databases (Shafei, 2018) study, and hence concluded by the need to pay attention to faculty members to obtain better educational outcomes, and with a study (Pham and Starkey, 2016), which its results indicate that the participants perceive quality closely as meeting the societal needs of individuals and producing appropriate educational specifications and standards.

In addition, the results of hypothesis testing also revealed that there is a statistically significant effect of the digital access divide on the quality of education, due to the presence of alternatives that are still used in universities of higher education, as well as parallel with the use of modern technologies to search for and obtain information. Therefore, this differs with the study of the Bagoor (2016) where the results indicated that there is an impact between information technology and the quality of higher education in its various dimensions, in addition to the presence of a statistically significant effect of the digital capacity divide on the quality of university education, "Due to the ability of the digital world, networks and databases to access and achieve tangible results on the quality of education and the outputs related to it. Hence, this differs with the study of Asoul (2016), whose results indicated that communication and information technology has a great role in the quality of higher education for its users represented in libraries and databases. Besides, there is also a statistically significant effect of the digital results divide on the quality of university education, which is consistent with the Bagoor study (2016), whose the results indicated that there is an effect between information technology and the quality of higher education in its various dimensions. On the other hand, this study recommends the necessity of providing basic resources (material, financial, technological and organizational in universities to serve students and faculty members, because the world is witnessing the trend towards the digital world, which is making qualitative leaps in the field of education, focusing on the quality of services for scientific research, as it needs the availability of the Internet and databases that contribute to the improvement of scientific research and the services 
INTERNATIONAL JOURNAL OF ACADEMIC RESEARCH IN BUSINESS AND SOCIAL SCIENCES

Vol. 10, No. 11, 2020, E-ISSN: 2222-6990 @ 2020 HRMARS

provided in this field, and making contributions that work on developing education; besides paying attention to training faculty members and providing them with computer and technical programs and the necessary training for their uses, refining their skills and developing them continuously, in order to improve education and promote it.

\section{References}

Adhikari, J., Mathrani, A., \& Scogings, C. (2016). Bring Your Own Devices classroom. Interactive Technology and Smart Education, 13(4), 323-343.

Al Thani, F. B. H., \& Obeidat, A. M. (2020). The Impact of Strategic Leadership on Crisis Management. International Journal of Asian Social Science, 10(6), 307-326.

Al-Ahmad, Ahmad, Omar \& Magda, W. A. (2018), The Digital Divide as One of the Contemporary Ethical Problems, Studies, Human and Social Sciences, 45(2) 61-71.

Al-Ali, S. (2017) The Reality of Implementing Total Quality Management in the Faculty of Arts at the University of Damascus, Al-Baath University Journal, 39( 7)

Aljawarneh, N. M., Sokiyna, M., Obeidat, A. M., Alomari, K. A. K., Alradaideh, A. T., \& Alomari, Z. S. (2020). The Role of CRM fog computing on innovation and customer service quality: An empirical study.

Al-Khatib, A. (2013), Developing a model for Accreditation and Quality Control in Higher Education Institutions in the Arab world. Damascus University Journal, 29 (2) 93-51.

Al-Qudah, S., Obeidat, A. M., \& Shrouf, H. (2020). The impact of strategic human resources planning on the organizational performance of public shareholding companies in Jordan. Problems and Perspectives in Management, 18(1), 219.

Karima, A. (2017) Analyzing the Digital Divide in Algeria Through the Digital Access Index, Journal of the University Islamic College, Iraq, 44, 575-606.

Badrakhan, S. S. E. (2013), The Extent to Which Al-Ahliyya Amman University Applies Quality Standards and Quality Assurance From the Faculty Members' Point of View. Al-Balqa Research and Studies, 16 (1). 59-87.

Dewan, S., and Frederick, J. R. (2005), "The digital divide: Current and future research directions", Journal of the Association for Information Systems, 6( 12) 298-336

Darwish, S., Ahmed, U., \& Pahi, M. H. (2020). Innovative Work Behavior During COVID-19 for Medical Representative in the Pharmaceutical Industry: Test of a Moderation Model in Bahrain. International Journal of Pharmaceutical Research. 12(4), 19271934. doi.org/10.31838/ijpr/2020.12.04.277

Flicking, Emilie \& Tarouana, A. Y. (2018), The Degree of Quality Assurance Standards for Jordanian Universities, Dirasat Journal, 45(3)

Noureddine, H., \& Mohammad, A-A. (2012) The Importance of Implementing Total Quality Management in Higher Education Institutions, Fourth Annual Conference of the Arab Organization for Quality Assurance in Education, Smart Village, Cairo, Egypt.

Irtaimeh, H. J., Obaidat, A., \& Khaddam, A. (2016). Strategic Role of Dashboard Application in Enhancing Crisis Management Capabilities in Organizations Field Study on Jordanian Cellular Companies. International Journal of Management Sciences and Business Research.5(10)50-59

Kantabutra, S. (2010), Vision effects: A critical divide in educational leadership research", International Journal of Educational Management, 24 ( 5) 376-390. 
INTERNATIONAL JOURNAL OF ACADEMIC RESEARCH IN BUSINESS AND SOCIAL SCIENCES

Vol. 10, No. 11, 2020, E-ISSN: 2222-6990 @ 2020 HRMARS

Krause, K. (2012). Addressing the Wicked Problem of Quality in Higher Education: Theoretical Approaches and implications. "Higher Education Research and Development 31 (3): 285-297

Madi, I. (2011) The Role of Knowledge Management in Ensuring Quality Higher Education. A case study at the Islamic University of Gaza, unpublished MA Thesis, Faculty of Commerce, Islamic University, Gaza, Palestine.

Mahameed, R.(2008), The Role of Knowledge Management in Achieving Quality Assurance in Higher Education, An Applied Study in Private Jordanian Universities, Master Thesis, College of Administrative and Financial Sciences,: Middle East University, Amman, Jordan.

Mahfodh, A. B. S. B., \& Obeidat, A. M. (2020). Knowledge Sharing Tools and their Impact on Enhancing Organizational Performance. International Journal of Academic Research in Business and Social Sciences. 10(9), 91-112.

Malkawi, N. M., Baniata, M. I., \& Obeidat, A. M. (2017). The Impact of E-Government Applications on Decision-Making Effectiveness: Case Study at Jordanian Ministry of InteriorJordan. International Review of Management and Business Research, 6(1), 172.

Mohammad, M. H. (2017). The Implications of Information Technology Capabilities in the Quality of University Education: A Case Study at the College of Engineering / University of Kirkuk. The Iraqi Journal of Information Technology, 8 (1), 116-144.

Munasinghe, M., \& Rathnasiri, U. (2011). "Undergraduates Perception on Quality of Higher Education. "Proceedings of International Conference on Qualitative and Quantitative Economics Research (QQE). Singapore: Global Science and Technology Forum.

Obeidat, A. (2019). IT Adaption with Knowledge Conversion Process (SECI)?. Management Science Letters, 9(13), 2241-2252.

Obeidat, A. M., \& Otibi, G. A. (2015). The impact of knowledge sharing tools on levels of organizational learning (Field Study on Jordanian Commercial Banks). Australian Journal of Basic and Applied Sciences, 9(5), 253-267.

Park, E.-A. and Lee, S. (2015), "Multidimensionality: Redefining the digital divide in the smartphone era", info, 17 ( 2) 80-96.

Ruzevicius, J., Adomaitiene, R., Serafinas, D., and Daugviliene, D. (2007). Peculiarities of Education Quality Assurance in Lithuania. Asian Journal on Quality, 8(2), 1-19.

Saffar, N., \& Obeidat, A. (2020). The effect of total quality management practices on employee performance: The moderating role of knowledge sharing. Management Science Letters, 10(1), 77-90.

Shrouf, H., Al-Qudah, S., Khawaldeh, K., Obeidat, A., \& Rawashdeh, A. (2020). A study on relationship between human resources and strategic performance: The mediating role of productivity. Management Science Letters, 10(13), 3189-3196.

Venkatraman, S. (2007), "A framework for implementing TQM in higher education programs", Quality Assurance in Education, 15 (1) 92-112.

Yu, B., Ndumu, A., Mon, L. M., and Fan, Z. (2018), "E-inclusion or digital divide: an integrated model of digital inequality", Journal of Documentation, 74(3), 552-574. 